\title{
Desafios na implementação do plano de gerenciamento de resíduos de serviços de saúde em hospitais
}

O plano de gerenciamento de resíduos de serviços de saúde (PGRSS) é o documento que aponta e descreve as ações relativas ao manejo dos resíduos dos serviços de saúde (RSS). O presente estudo teve como objetivo analisar os desafios da implementação do PGRSS em quatro unidades hospitalares. A pesquisa fo desenvolvida em quatro hospitais de pequeno porte $(\mathrm{H} 1, \mathrm{H} 2, \mathrm{H} 3$ e H4) na mesorregião do leste rondoniense, ou seja que possuem até 50 leitos de internação. $\mathrm{O}$ procedimento metodológico empregado obedeceu o seguinte: (1) análise documental do PGRSS, (2) visitas a todos os setores dos hospitais observando-se e registrando-se os procedimentos de manejo dos RSS sendo anotados em diário de campo e tabela observacional e (3) a quantificação dos RSS gerados na primeira semana do mês no período de seis meses. Os resultados indicaram, que nenhum dos quatro hospitais possui o PGRSS completo com todas as informações exigidas na RDC 306/2004. Com as visitas identificou-se que os quatro hospitais possuem várias dificuldades em todas as etapas operacionais do manejo do RSS. A taxa de geração de 0,199 kg de RSS/leito ocupado/dia para o H2, a taxa de geração de 0,403 kg de RSS/leito ocupado/dia para o H1, 1,642 kg de RSS/leito ocupado/dia para o H3, 3,009 kg de RSS/leito ocupado/dia para o H4 sendo o hospital que apresentou a maior taxa de geração de resíduos. Concluiu-se que os principais desafios para realizar a implementação do PGRSS vai desde a sua elaboração que está desconectada da operacionalização, baixo conhecimento dos profissionais envolvidos no manejo dos RSS sobre as legislações que determina como é realizado cada etapa do manejo dos RSS e ausência de capacitação técnica dos profissionais.

Palavras-chave: Resíduos Sólidos; Meio Ambiente; Manejo de resíduos de serviços de saúde; Hospitais.

\section{Challenges in the implementation of the health services residual management plan in hospitals}

\begin{abstract}
The health services waste management plan (PGRSS) is the document that identifies and describes actions related to the treatment of health services (RSS). The present study aimed to analyze the challenges of the implementation of the PGRSS in four hospital units. The evaluation was carried out in four medium-sized hospitals $(\mathrm{H} 1, \mathrm{H} 2, \mathrm{H} 3$ and $\mathrm{H} 4)$ in the eastern region of Rondônia, that is, up to 50 hospitalization beds. The data method on the obedience to the following method: (1) analysis of the PGRSS, (2) visits to the document testing and the observation-and-testing the manual processing the RSS from 3) a quantification of the generated in the first week of the month in a period of six months. The results indicate that, in any of the four countries, it has PGRSS with all the information required in DRC $306 / 2004$. With the same identifications that the moon has several difficulties in all operational stages of RSS. Generation rate of $0,199 \mathrm{~kg}$ of RSS / number occupied per day for $\mathrm{H} 2$, generation rate of $0.403 \mathrm{~kg}$ of RSS / number occupied per day for $\mathrm{H} 1$ of 1,642 kg of RSS / number occupied per day for H3 of 3,009 $\mathrm{kg}$ of RSS / bank occupied / day for the $\mathrm{H} 4$ being the hospital that presented a higher rate of waste generation. It was concluded that the main challenges to carry out an implementation of the PGRSS from its elaboration that is disconnected from the operationalization, part of the knowledge of the professionals involved in the management of RSS as the legislation that determines the accomplishment of each phase of the management of RSS and absence of technical training of professionals.
\end{abstract}

Keywords: Solid Waste; Environment; Management of waste health services; Hospitals.

Topic: Engenharia Ambiental

Reviewed anonymously in the process of blind peer.
Received: 02/12/2018

Approved: $26 / 01 / 2019$
Carina Sena Padovan Ishida (iD)

Universidade de Taubaté, Brasil

http://lattes.cnpq.br/3302526704869843

http://orcid.org/0000-0002-1244-8027

caripadovan@hotmail.com

Ana Aparecida da Silva Almeida

Universidade de Taubaté, Brasil

http://lattes.cnpq.br/7440206313187404

anaparecida.almeida@gmail.com

\section{Referencing this:}

ISHIDA, C. S. P.; ALMEIDA, A. A. S.. Desafios na implementação do plano de gerenciamento de resíduos de serviços de saúde em hospitais. Revista Ibero Americana de Ciências Ambientais, v.10, n.1, p.110-130, 2019. DOI: http://doi.org/10.6008/CBPC21796858.2019.001.0010 


\section{INTRODUÇÃO}

A geração e destinação final dos resíduos de serviços de saúde (RSS), produzidos pelos diversos estabelecimentos de saúde tem sido um desafio para o Brasil, sendo a gestão dos RSS de extrema importância pois o descarte inadequado desses resíduos podem causar danos ambientais capazes de colocar em risco a qualidade de vida da população (MELO et al., 2014).

Apesar do plano de gerenciamento dos resíduos em serviços de saúde (PGRSS) ter sido estabelecido há mais de uma década pela RDC no 306/04 (BRASIL, 2004) e pela resolução CONAMA no 358/05 (BRASIL, 2005), na prática ainda não se observa a implementação de um plano gerencial adequado ou a sua existência quer seja por razões de infraestrutura, recursos financeiros, recursos humanos ou conhecimento (PEREIRA et al., 2013).

O PGRSS é o documento que aponta e descreve as ações relativas ao manejo dos resíduos dos serviços de saúde, observadas suas características e riscos no âmbito dos estabelecimentos, contemplando os aspectos referente à geração, segregação, acondicionamento, coleta, armazenamento, transporte, tratamento e disposição final, bem como as ações de proteção à saúde pública e ao meio ambiente. Tem como objetivo minimizar a produção de resíduos e proporcionar aos resíduos gerados, um encaminhamento seguro, de forma eficiente, visando à proteção dos trabalhadores, a preservação da saúde pública, dos recursos naturais e do meio ambiente (BRASIL, 2004).

O treinamento inadequado na gestão dos RSS, ou a ausência de gestão de RSS e de sistemas de eliminação, a limitação de recursos financeiros e/ou humanos e a baixa prioridade dada a gestão dos RSS são problemas comuns relacionados a saúde ambiental. De acordo com o princípio do 'poluidor-pagador', a responsabilidade do manejo dos RSS recai sobre o produtor de resíduos, geralmente o prestador de cuidados de saúde, ou o estabelecimento envolvido em atividades relacionadas. Para alcançar uma gestão segura e sustentável dos RSS, análises financeiras devem incluir todos os custos da sua disposição final (WHO, 2011).

Em vários estudos são frequentes os relatos de que o gerenciamento de RSS apresenta várias dificuldades em suas etapas operacionais (PEREIRA et al., 2013; CASTRO et al., 2014; SILVA et al., 2014; OLIVEIRA et al., 2014; MELO et al., 2014). Segundo Alves (2012) a segregação inadequada desencadeia prejuízos decorrentes de aumento no custo para o descarte dos RSS. Pereira et al. (2013) destacam que a presença de material perfurocortante acondicionado em sacos sem qualquer proteção revelam que os profissionais das unidades de saúde não incorporaram, em sua prática, a adequada segregação dos RSS.

Para Silva et al. (2014) a falta de recipientes para acondicionar os sacos contendo RSS, ficando esses dispostos diretamente sobre o piso na maioria dos estabelecimentos, indica a necessidade de investir em equipamentos para melhorar o gerenciamento dos RSS e regularizar a situação perante a legislação. No transporte dos RSS a inexistência e inadequação dos carros coletores para transporte interno pode ocasionar risco de acidente aos trabalhadores e/ou excesso de esforço físico, bem como a falta de horários préestabelecidos, para a distribuição de roupas, alimentos e medicamentos, amplia o risco para além dos funcionários da instituição, como visitantes, acompanhantes e pacientes (CASTRO et al., 2014). 
A falta de abrigo externo para os RSS em vários estabelecimentos de saúde agrava ainda mais a situação encontrada, pois os resíduos são deixados expostos ao tempo, a curiosos e até a catadores, que desconhecem os riscos inerentes a esse tipo de resíduo (SILVA et al., 2014). O armazenamento externo inadequado dos RSS expõe a riscos toda a população, principalmente os indivíduos que procuram meios de sobrevivência no lixo, pois é frequente, pessoas revirando o container destinado aos resíduos comuns, a fim de encontrarem algo que possa ser reciclado e funcione como fonte de renda. Além disso, resíduos dispostos em locais inapropriados favorecem o aparecimento de roedores, vetores e outros animais (PEREIRA et al., 2013).

A Mesorregião do Leste Rondoniense agrega 61,0\% da renda estadual (BRASIL, 2008) sendo composta por 42 municípios, com área 129.600,165 km sendo a maior territorialmente com população de 950.720 habitantes com densidade de $8,0 \mathrm{hab} / \mathrm{km}^{2}$ (IBGE, 2008). Dentre estes municípios destacam-se JiParaná, Cacoal e Ouro Preto do Oeste.

O município de Ji-Paraná tem população de 132.667 habitantes em uma área territorial de 6.896,604 $\mathrm{km}^{2}$. Enquanto Cacoal tem população de 88.507 habitantes em uma área territorial $3.792,948 \mathrm{~km}^{2}$. E o município de Ouro Preto do Oeste tem população de 39.759 habitantes em uma área territorial de 1.969,850 $\mathrm{km}^{2}$ (IBGE, 2008).

Segundo o DATASUS (2017) o estado de Rondônia dispõe de 110 hospitais, 73 do Sistema Único de Saúde (SUS) com 3.279 leitos e 39 particulares com 975 leitos totalizando 4.254 leitos hospitalares. A distribuição dos hospitais e leitos nos municípios de Ouro Preto do Oeste, Cacoal e Ji-Paraná é de 4, 87, 8, 380 e 9,308 , respectivamente .

Segundo a ABRELPE (2015) significativa parcela dos municípios brasileiros coletam e dão destinação final apenas para os RSS gerados em unidades públicas de saúde não havendo informações oficiais sobre os RSS dos serviços de saúde privados. É sob esta ótica que se observou uma redução de 1,5\% na quantidade de RSS coletados pelos municípios brasileiros em 2015/2016. Constatou-se ainda que $25,7 \%$ dos municípios brasileiros ainda destinaram os RSS coletados sem declarar o tratamento prévio dado aos mesmos, o que contraria as normas vigentes e apresenta riscos diretos aos trabalhadores, à saúde pública e ao meio ambiente.

Para vários autores observa-se na prática que a falta de informações referentes aos resíduos produzidos nos estabelecimentos de saúde principalmente nos privados, adequação e coordenação dos processos de gerenciamento de resíduos, obedecendo às legislações, a falta de infraestrutura, baixa utilização de tratamentos prévios, uso de técnicas inadequadas de disposição final, ausência de programas de reciclagem, ausência de treinamento das equipes de saúde são os desafios frequentemente encontrado para a implantação efetiva do PGRSS (RIZZON et al., 2015; MENDONÇA, 2017; SODRÉ et al., 2017).

Assim a questão da gestão dos RSS é de relevância tanto no contexto da segurança dos profissionais de saúde e da preservação e conservação do meio ambiente como no âmbito da construção de novos paradigmas de atenção à saúde. Neste sentido, a fim de ampliar a discussão no que se refere a esta temática, 
este estudo tem por objetivo central a análise dos desafios da implementação do plano de gerenciamento de RSS em quatro hospitais da Mesorregião do Leste Rondoniense.

\section{REVISÃO TEÓRICA}

\section{Dificuldades no Plano de Gerenciamento de Resíduos de Serviços de Saúde (PGRSS)}

Atualmente o gerenciamento integrado dos RSS possui desafios de operacionalização de sistemas especificamente adequados de gerenciamento de RSS a cada tipo de organização, independentemente de sua natureza ou tamanho (MELO et al., 2014). De acordo com ABRELPE (2015) a geração total de resíduo sólido urbano (RSU) no Brasil teve uma redução de $2 \%$ em relação a 2015 sendo coletados aproximadamente 71,3 milhões de toneladas, destes $29,7 \mathrm{t}$.ano foram destinados para locais inadequados como lixões ou aterros controlados, que não possuem o conjunto de sistemas e medidas necessários para proteção do meio ambiente contra danos e degradações, sendo $1 \%$ a $2 \%$ dessa quantidade produzida nos estabelecimentos de saúde. Nos municípios brasileiros foram coletados 256.238 mil toneladas de RSS com índice 1,24 kg/hab/ano revelando uma redução de 1,47\% , o processo realizado para o tratamento em 2016 pelos municípios t.ano ocorreram em autoclave 192.319, incineração 114.026 e micro-ondas 56.940 totalizando 363.285 . O mesmo relatório identifica que $25,7 \%$ dos municípios brasileiros destinaram seus RSS sem declarar o tratamento prévio dado aos mesmos.

Segundo o Programa Nacional de Saneamento Básico-PNSB (2008) 50,8\% os municípios brasileiros realizam a destinação final dos resíduos sólidos nos vazadouros a céu aberto (lixões), 22,5 \% em aterros controlados e $27,7 \%$ em aterros sanitários. A destinação final desses resíduos em lixões registram maior proporção para Regiões Nordeste 89,3\% e Região Norte 85,5\% a menor proporção ficou nas Regiões Sul $15,8 \%$ e Sudeste $18,7 \%$.

Segundo a WHO (2011) e ABRELPE (2015) os materiais que entram em contato com o sangue e outros fluidos corpóreos constituem-se de elevado potencial de infecção e configura-se em impactos ao meio ambiente, pois a decomposição dos materiais gera substâncias altamente tóxicas que contaminam diretamente o solo, as águas, o ar e, pior do que tudo, as pessoas, quando não é realizado o manejo adequado dos resíduos.

Kneipp et al. (2011) identificaram a não ocorrência de treinamentos específicos promovidos pelos hospitais para os profissionais de saúde quanto a responsabilidade no processo do gerenciamento RSS. Bento et al. (2017) salientam que pela lacuna de conhecimento e pouco ser abordado a temática dos RSS no meio acadêmico e ausência no ambiente de trabalho de capacitações, os profissionais não conhecem os símbolos utilizados para identificar os locais para o descarte dos RSS perfurocortantes e material biológico. Apesar dos profissionais envolvidos com o manejo dos RSS alegar conhecimento sobre Resolução 306/2004 (BRASIL, 2004), muitos ainda possuem conhecimentos fragmentados quanto às exposições, impactos à saúde, medidas de prevenção, terminologias e disposição final dos RSS (DOI et al., 2011). 
Para Pereira et al. (2013) é importante enfatizar que pouca importância é dada ao manejo dos perfurocortantes que são responsáveis por muitos casos de acidentes envolvendo os profissionais que trabalham com os RSS. Estes resíduos de serviços de saúde, embora potencialmente infectantes e perigosos, são atualmente passíveis de tratamento e manejo seguro. Sendo assim, possível prevenir e minimizar os efeitos potencialmente agressivos destes resíduos quanto ao meio ambiente e à saúde humana, por meio de medidas de preservação ambiental e de políticas de saúde pública (CENTENARO et al., 2012). Vários autores relatam que a falta de conhecimento no manejo dos resíduos reflete no gerenciamento inadequado destes, repercutindo de forma direta na saúde ocupacional dos trabalhadores em saúde (DUTRA et al., 2012; MULLER et al., 2013).

Segundo Pereira et al. (2013) os estabelecimentos de saúde devem realizar investimentos em cursos e capacitações para os profissionais envolvidos com os RSS sendo de suma importância, visto que, a partir do momento que estes profissionais conhecem as normas e legislações vigentes estes passam a realizar o manejo correto dos RSS reduzindo despesas com o destino final do RSS.

Todos os profissionais que trabalham no serviço, envolvidos nas atividades de gerenciamento de resíduos, devem conhecer o manejo dos RSS, a prática de segregação de resíduos, reconhecer os símbolos, expressões, padrões de cores adotados, conhecer a localização dos abrigos de resíduos, entre outros fatores indispensáveis à completa integração ao PGRSS. Evidencia-se, assim a necessidade de treinamento e capacitação dos recursos humanos envolvidos no gerenciamento de RSS (GESSNER, 2013)

Quanto à segregação, os resíduos são descartados de maneira inadequada não realizando a coleta seletiva, podendo promover a contaminação de todo o resíduo descartado (NITSCHE et al., 2014). Para Castro et al. (2014) na fase de segregação, as unidades de saúde não separam os RSS no momento do uso, com exceção dos perfurocortantes (Grupo E).

De acordo com Dutra et al. (2012) a ausência da segregação acarreta a mistura dos RSS ocorrendo o acondicionamento dos RSS comuns e biológicos (Grupos D e A). Para Bianchi et al. (2017) e Mahler et al. (2017) as principais falhas na segregação ocorre pelo baixo nível de conhecimento, dos profissionais para identificar na segregação quais são os resíduos dos Grupos A, D e E. Para Souza et al. (2015) os resíduos com risco químico (Grupo B) não são citados nos estabelecimentos de saúde e são descartados sem a devida segregação.

Considerando todas as etapas no manejo dos resíduos, entre as mais crítica e importante, está a segregação, pois nesta dependemos do conhecimento e da ética do profissional que deve estar ciente do seu papel no processo da classificação prévia e da correta separação do RSS (OPAS, 1997; WHO, 2014). Para Mahler et al. (2017) é indispensável que seja preconizado na instituição a adequada segregação dos RSS, já que devido as características patogênicas dos RSS quando não manipulados de forma adequada, estes podem se configurar como potencial risco ao meio ambiente, saúde do trabalhador e à saúde pública.

Essa segregação inadequada desencadeia prejuízos decorrentes como, aumento no custo para o descarte dos resíduos, possibilidade de risco para os trabalhadores e usuários, além de danos ambientais (ALVES et al., 2012; ROSA, 2015; SILVA, 2015). Para Silva et al. (2017) os resíduos devem ser tratados 
conforme suas classificações, quando a segregação não ocorre no momento e local da sua geração todos os resíduos se tornam infectantes.

No acondicionamento verifica-se que as unidades não dispõem de sacos plásticos e contenedores adequados para fazerem o acondicionamento correto dos seus resíduos, procedimento imprescindível ao gerenciamento correto dos RSS (OLIVEIRA, 2014). Gomes et al. (2012) identificaram que os estabelecimentos de saúde acondicionavam os RSS em garrafas PET, tonéis plásticos adaptados e os sacos plásticos destinados para receber os RSS eram os utilizados para RSU e não possuíam nenhum tipo de identificação, o descarte dos RSS era combinado com os RSU criando situação de risco para os funcionários da coleta e impacto ambiental. Para Souza et al. (2015) os resíduos biológicos do (Grupo A) e perfurocortantes (Grupo E) ocorrem com maior frequência. Nota-se que esse fato relaciona-se a não adequação do manejo nas etapas anteriores, pois a ausência de segregação adequada influencia diretamente na etapa de identificação dos RSS (CASTRO et al., 2014).

Para que a segregação e o acondicionamento ocorra de forma adequada a identificação deve estar aposta nos sacos de acondicionamento, nos recipientes de coleta interna e externa, nos recipientes de transporte interno e externo, e nos locais de armazenamento, em local de fácil visualização, de forma indelével, utilizando-se símbolos, cores e frases, atendendo aos parâmetros referenciados na norma NBR 7.500 da ABNT, além de outras exigências relacionadas à identificação de conteúdo e ao risco específico de cada grupo de resíduos. (BRASIL, 2004). Quanto à identificação dos RSS, vários autores relatam que os recipientes como equipamentos para o transporte interno, abrigo externo e o veículo coletor, não possuíam a identificação adequada o que leva a segregação e a quantificação de RSS ser inadequada (DUTRA et al., 2012; NITSCHE et al., 2014; SILVA et al., 2014; CASTRO et al., 2014).

A coleta de resíduos nas unidades, frequentemente, coincide com os horários de distribuição de roupas e visita de acompanhantes e no transporte interno os RSS não são identificados (DUTRA et al., 2012). Castro et al. (2014) identifica que quanto a coleta e o transporte interno dos RSS, é frequente a falta de definição de horários, turnos e frequência de coletas. O transporte é realizado de maneira manual, não havendo disposição de carrinho coletor identificado com o símbolo de cada resíduo. Não há uso de equipamentos de proteção individual necessários para a atividade, fazendo uso apenas de botas, máscara e luvas (GOMES et al., 2012).

Silva et al. (2014) identificaram que ao coletar os RSS vários sacos eram carregados ao mesmo tempo o que dificulta mantê-los distantes do corpo, as mãos e cabo de vassoura são utilizados para compactar os resíduos dentro dos recipientes de coleta e dentro dos veículos, levando ao rompimento com vazamento do conteúdo, a troca de recipientes acima de $100 \mathrm{~L}$ acarreta um grande esforço físico aumentando os riscos de contato com os RSS podem comprometer a saúde do trabalhador e colocá-lo em riscos.

Quanto ao armazenamento temporário é comum não serem exclusivos para o armazenamento dos RSS gerados e o espaço não atende a legislação não existindo tratamento dos RSS nos hospitais. O abrigo se encontra sem identificação, está subdimensionado para receber e armazenar o quantitativo de RSS do hospital, não está projetado ou dividido por grupo de resíduo (são colocados juntos sem qualquer controle), 
não há local para segregação e não há ventilação ou exaustão dos gases gerados. Verifica-se também falta de iluminação adequada, além de não atendimento aos circuitos de força, como tomadas. Não há escoamento adequado das águas de lavagem e a porta de entrada não impede a entrada de vetores como roedores (DUTRA et al., 2012).

Ramos et al. (2011) e Melo et al. (2014) relatam que o tratamento prévio do RSS muitas vezes não ocorre como o previsto nos instrumentos legais. Alguns estabelecimentos realizam incineração, queima em céu aberto e outros não realizam nenhum tipo de tratamento do RSS (ADUAN, 2014; SOUZA et al., 2015). De acordo com Silva et al. (2014) o descarte inadequado dos RSS traz efeitos adversos a diferentes ecossistemas, configurando um grave problema de saúde pública. Ramos et al. (2011) em seus trabalhos encontraram falhas nos armazenamentos externos que apresentavam deficiências de infraestruturas nas instalações elétricas e hidráulicas, ventilação inexistente e ausência de baias individualizadas para separar os vários tipos de resíduos (comuns e infectantes).

Para Macedo et al. (2013) a localização dos armazenamentos externos também não possuem restrição de acesso a pessoas estranhas, as características físicas e dimensões são insuficientes pelo volume de RSS gerados. Verifica-se também falta de escoamento adequado das águas de lavagem e a porta de entrada não impede a entrada de vetores como roedores. Devido ao subdimensionamento dos armazenamentos externos, são utilizados containers tipo caçamba onde os resíduos são colocados e muitos destes containers permanecem ao ar livre, abertos e sem proteção contra insetos e outros vetores (DUTRA et al., 2012).

Castro et al. (2014) relatam que a coleta e o transporte externo dos resíduos não são realizados em horário específico, tampouco os trabalhadores utilizam rigorosamente os equipamentos de proteção individual e coletiva a disposição final do RSS ocorriam em um lixão a céu aberto, excetuando-se os resíduos do grupo A3 que eram depositados nas cisterna no pátio do hospital, por último.

Segundo Silva et al. (2014) ao se analisar a situação do gerenciamento do RSS encontrada nos municípios, verifica-se a necessidade de se investir em treinamento dos gestores responsáveis pelo gerenciamento dos RSS, principalmente em relação ao conhecimento da legislação, e desta forma garantir a implementação de procedimentos e técnicas que assegurem a saúde do trabalhador e a proteção do meio ambiente.

\section{MATERIAIS E MÉTODO}

\section{Local da pesquisa}

A pesquisa foi desenvolvida nas cidades de Ji-Paraná (Latitude: 10 53' 07" S, Longitude: 61ㅇ 57' 06" W), Cacoal (Latitude: 11 26' 19" S, Longitude: 61 26' 50" W) e Ouro Preto do Oeste (Latitude: 10 44' 53" S, Longitude: 62ํ12' 57" W) no estado de Rondônia (Figura 1). 


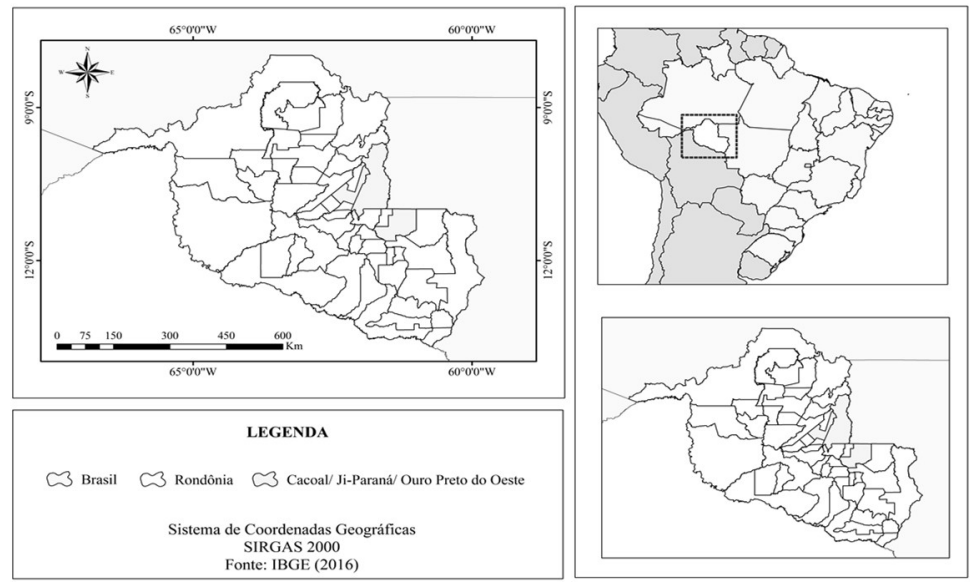

Figura 1: Mapa de localização dos municípios de Ji-Paraná, Cacoal e Ouro Preto do Oeste

\section{Comitê de Ética}

Atualmente, as diretrizes éticas nacionais para pesquisas envolvendo seres humanos estão definidas na Resolução 466/2012 do Conselho Nacional de Saúde (CNS). Para cumprir os preceitos éticos e legais da pesquisa e com foco nos critérios do consentimento livre e esclarecido, direitos dos participantes, responsabilidade do pesquisador, está pesquisa foi submetida e aprovada com número do Certificado de apresentação para apreciação ética (CAAE): 70608017.0.0000.5501.

\section{Estabelecimentos de Saúde}

A pesquisa foi desenvolvida em quatro hospitais de pequeno porte, ou seja que possuem até 50 leitos de internação (BRASIL, 1977). Os hospitais realizam atendimentos clínicos, cirúrgicos, obstétricos e de pediatria (DATASUS, 2015) e são instituições privadas, sendo: um hospital em Ji-Paraná com 46 leitos de internação; um hospital em Cacoal com 23 leitos de internação e dois hospitais em Ouro Preto do Oeste, totalizando 42 leitos.

\section{Procedimento Metodológico}

\section{Documentos e registros do PGRSS}

Foi realizado analise documental do PGRSS, utilizando como instrumento de coleta de dados um check lista constituído por nove categorias baseados na RDC no 306 (BRASIL, 2004). O check lista tinha como foco registrar as informações que devem estar detalhadas no PGRSS, como caracterização do estabelecimento de saúde, resíduos gerados, identificação, armazenamento, coleta e transporte interno, tratamento, capacitação do recursos humanos com roteiro de treinamento para o pessoal envolvido no gerenciamento de resíduos com comprovação de capacitação, contrato com empresa terceirizada, com termos de licitação, monitorar e avaliar o PGRSS, com analise dos indicadores anuais do PGRSS com o objetivo de ser uma fonte paralela e simultânea de informações dos hospitais a serem estudados.

Para cada item do check lista avaliado da categoria atribui-se pontuação de acordo com a descrição das informações totalmente descrito (TD) 1,0 ponto, parcialmente descrito (PD) 0,5 ponto e ausente (A) 0 
ponto. O valor total da somatória dos itens é de 38 pontos para um PGRSS com todos os itens descritos no check lista. A partir da análise das informações por categoria foram estabelecidos a pontuação e status do PGRSS, adaptando-se o status para as nomenclaturas completo, parcialmente completo e incompleto. Considerou-se PGRSS completo quando apresentava de $80,0 \%$ a $100,0 \%$ dos itens totalmente descritos; parcialmente completo, de $40,0 \%$ a $79,0 \%$ dos itens descritos; e incompleto, com $39,0 \%$ ou menos dos itens descritos (MENDONÇA et al., 2017).

\section{Visita aos setores do estabelecimento de saúde}

Foi realizada visitas a todos os setores dos hospitais: Clínica Médica, Cirúrgica, Maternidade, Pediatria, Unidade de Terapia Intensiva Adulta (UTI), Centro Cirúrgico, Central de Material e Esterilização, Atendimento de Emergência, Serviços de Nutrição e Dietética, Lavanderia, Farmácia e Almoxarifado, Setor de imagem, Setores Administrativos, Comissão de Controle de Infecção Hospitalar, Chefia de Enfermagem, Diretores Administrativos e Hospitalar com o objetivo de identificar as dificuldades e facilidades das fontes geradoras, caracterizando os RSS, observando os procedimentos geração, segregação, acondicionamento, coleta, transporte, tratamento e destino final dos resíduos sendo anotados em diário de campo e tabela observacional no momento dos acontecimentos. Paralelamente visando avaliar o manejo dos RSS, de acordo com a Resolução ANVISA RDC 306/2004 (BRASIL, 2004).

Foi observado o comportamento dos profissionais envolvidos com as etapas da geração, segregação, acondicionamento, identificação, transporte interno, armazenamento temporário, tratamento, armazenamento externo dos RSS biológico, químico, perfurocortantes e comuns e de outros tipos de resíduos, dos cuidados dispensados nas etapas do manejo dos RSS, pelos funcionários da higienização e limpeza hospitalar, equipe de enfermagem, independente do sexo, idade ou tempo de serviço com o estabelecimento de saúde, todas as observações foram registradas em diário de campo e tabela observacional conforme apêndice 2 (RIZZON et al., 2015).

\section{Pesagem dos Resíduos dos Serviços de Saúde}

A quantificação dos RSS gerados nos estabelecimentos de saúde foram pesados durante sete dias sempre na primeira semana do mês no período de 24 horas, no período de seis meses, sendo necessário a pesagem dos RSS em vários momentos sendo separados e pesados por funcionários selecionados, orientados e supervisionados conforme apêndice 3 .

O resultado das pesagens foram registrados em planilhas permitindo conhecer a caracterização e o montante dos RSS gerados diariamente por cada estabelecimento de saúde. A contagem diária dos pacientes internados de todos os setores foi realizada tendo como fonte de informação o censo hospitalar. Este controle foi executado durante sete dias sempre na primeira semana do mês nos quatro hospitais pesquisados. 


\section{RESULTADOS}

\section{Documentos e registros do PGRSS}

O PGRSS dos hospitais foram disponibilizados em arquivos digitais, a partir da leitura e análise, foi preenchido o check lista de nove categorias (MENDONÇA, 2017). Foi possível analisar os itens preenchidos no check lista como segue no quadro 2 constatando-se que nenhum dos hospitais possui a descrição completa de todos os itens avaliados. A categoria monitorar e avaliar não foi mencionada em nenhum dos estabelecimentos de saúde, a identificação foi a única completa no PGRSS dos quatro estabelecimentos.

Quadro 1: Análise dos itens descritos nos planos de gerenciamento de resíduos de serviços de saúde (PGRSS) de quatros hospitais $(\mathrm{H} 1, \mathrm{H} 2, \mathrm{H} 3$ e H4) da mesorregião do leste rondoniense. Células preenchidas na cor cinza escuro indicam que o item foi totalmente descrito no PGRSS; em cinza claro parcialmente descrito no PGRSS e em branco indica ausência de descrição do item no PGRSS.

\begin{tabular}{|c|c|c|c|c|}
\hline Categorias avaliadas no PGRSS & H01 & 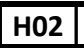 & $\mathrm{HO3}$ & $\mathrm{HO4}$ \\
\hline \multicolumn{5}{|l|}{ Caracterização do Estabelecimento de Saúde } \\
\hline \multicolumn{5}{|l|}{ Identificação do estabelecimento de saúde } \\
\hline \multicolumn{5}{|l|}{ Responsável pelo estabelecimento de saúde } \\
\hline \multicolumn{5}{|l|}{ Responsável técnico do PGRSS } \\
\hline \multicolumn{5}{|l|}{ Certificado de Responsabilidade Técnica } \\
\hline \multicolumn{5}{|l|}{ Número de leitos } \\
\hline \multicolumn{5}{|l|}{ Unidades de serviços } \\
\hline \multicolumn{5}{|l|}{ Objetivos gerais } \\
\hline \multicolumn{5}{|l|}{ Diagnostico situacional } \\
\hline \multicolumn{5}{|l|}{ Segurança do trabalhador EPI e EPC } \\
\hline \multicolumn{5}{|l|}{ Resíduos Gerados } \\
\hline \multicolumn{5}{|l|}{ Caracterização dos resíduos gerados } \\
\hline \multicolumn{5}{|l|}{ Segregação para os resíduos dos grupos $A, B, C, D, E$} \\
\hline \multicolumn{5}{|l|}{ Acondicionamento para os resíduos dos grupos $A, B, C, D, E$} \\
\hline \multicolumn{5}{|l|}{ Identificação } \\
\hline \multicolumn{5}{|l|}{ Identificação dos sacos e recipientes } \\
\hline \multicolumn{5}{|l|}{ Identificação dos recipientes de coleta interna e externa } \\
\hline \multirow{2}{*}{\multicolumn{5}{|c|}{$\begin{array}{l}\text { Identificação dos locais de armazenamento } \\
\text { Armazenamento, coleta e transporte interno }\end{array}$}} \\
\hline & & & & \\
\hline \multicolumn{5}{|l|}{ Coleta e transporte } \\
\hline \multicolumn{5}{|l|}{ Roteiros para coleta } \\
\hline \multicolumn{5}{|l|}{ Recipientes para transporte } \\
\hline \multicolumn{5}{|l|}{ Armazenamento temporário } \\
\hline \multicolumn{5}{|l|}{ Armazenamento, coleta e transporte externo } \\
\hline \multicolumn{5}{|l|}{ Roteiro para traslado dos RSS } \\
\hline Armazenamento externo & & & & \\
\hline Tratamento & & & & \\
\hline Tipo de tratamento intra estabelecimento & & & & \\
\hline Tipo de tratamento extra estabelecimento & & & & \\
\hline Capacitação do Recursos Humanos & & & & \\
\hline Cronograma de treinamentos & & & & \\
\hline Lista de presença dos treinamentos & & & & \\
\hline Monitorar e avaliar o PGRSS & & & & \\
\hline Indicador taxa de acidentes com resíduo perfurocortante & & & & \\
\hline Indicador variação da geração de resíduos & & & & \\
\hline Indicador variação da proporção de resíduos do Grupo A, B C, D, E & & & & \\
\hline Indicador variação do percentual de reciclagem & & & & \\
\hline $\begin{array}{l}\text { Indicadores claros, objetivos, autoexplicativos e confiáveis que per } \\
\text { PGRSS }\end{array}$ & & & & \\
\hline Referências ao final do PGRSS & & & & \\
\hline Contrato com empresa terceirizada & & & & \\
\hline Apresentar o Certificado de Coleta de Resíduos - CCR & & & & \\
\hline Apresentar o e Certificado de Destinação Final de Resíduos - CDR & & & & \\
\hline
\end{tabular}


Como ocorre a coleta

Como ocorre o transporte

Como ocorre o tratamento

Como ocorre a destinação final

Conforme o quadro 2, no H3 das 9 categorias avaliadas a única informação totalmente completa no PGRSS foi sobre a identificação dos RSS, 71\% das informações foram ausentes e 11\% parcialmente completa, as informações completas totalizaram apenas $18 \%$ caracterizando o PGRSS como incompleto. O H1, H2 atingiram o percentual respectivamente de $32 \%$ de ausente, $16 \%$ parcialmente completo e $53 \%$ de informações completas, o H4 obteve $29 \%$ ausente, $8 \%$ parcialmente completas e $63 \%$ de informações completas sendo classificados como parcialmente completo. Nenhum estabelecimento de saúde atingiu a pontuação de $80 \%$ a $100 \%$ das informações do PGRSS preenchidas.

Quadro 2: Avaliação do Plano de Gerenciamento de Resíduos de Serviços de Saúde de hospitais, segundo escala, pontuação e status atribuídos dos quatros Hospitais da Mesorregião do Leste Rondoniense

\begin{tabular}{|l|l|l|l|l|l|}
\hline \multicolumn{2}{|l|}{ Escala } & \multicolumn{2}{|l|}{ Pontuação } & Status & \multicolumn{3}{l|}{ Hospitais } \\
\hline \multicolumn{2}{|l|l|l|}{} & H1 & H2 & H3 & H4 \\
\hline $00-39 \%$ & 00 a 12 & Incompleto & & & \\
\hline $40-79 \%$ & Parcialmente Completo 25 & Completo & & & \\
\hline $80-100 \%$ & 26 a 38 & & & \\
\hline
\end{tabular}

\section{Visita aos setores do estabelecimento de saúde}

A partir de várias visitas a todos os setores dos quatro hospitais por meio do preenchimento do formulário de observação sistemática foi analisado a prática dos profissionais envolvidos em todas as etapas do manejo conforme Quadro 3. Foi possível em todos os hospitais pesquisados identificar no comportamento dos funcionários da higienização, limpeza hospitalar e equipe de enfermagem ausência de conhecimento e por diversas vezes dificuldades de realizar o manejo dos RSS de acordo com o que determina a RDC no 306/2004 (BRASIL, 2004).

Quadro 3: Observação sistemática do manejo dos resíduos de serviços de saúde de quatros hospitais $(\mathrm{H} 1, \mathrm{H} 2, \mathrm{H} 3$ e H4) da mesorregião do leste rondoniense. Células preenchidas na cor cinza escuro indicam que o item foi identificado na prática do estabelecimento de saúde, em branco indica que o item não foi identificado na prática do estabelecimento de saúde.

\begin{tabular}{|c|c|c|c|c|c|c|}
\hline Etapas do manejo & H1 & H2 & H3 & H4 & $\begin{array}{l}\text { Não conformidades } \\
\text { observadas }\end{array}$ & Determinações legais \\
\hline Segregação & & & & & $\begin{array}{l}\text { Segregação não é } \\
\text { realizada no local da } \\
\text { geração do RSS. }\end{array}$ & $\begin{array}{l}\text { Resolução da ANVISA RDC no } 306 / 04 \text {, NBR } 12807 / 1993 \\
\text { determina que a separação dos RSS ocorra no momento e } \\
\text { local de sua geração, de acordo com as características físicas, } \\
\text { químicas, biológicas, estado físico e os riscos envolvidos. }\end{array}$ \\
\hline & & & & & $\begin{array}{l}\text { Os RSS estavam } \\
\text { ultrapassando o limite } \\
\text { 2/3 de sua capacidade. }\end{array}$ & $\begin{array}{l}\text { NBR } 12809 / 1993 \text { determina que todo recipiente tem que ser } \\
\text { fechado quando } 2 / 3 \text { de sua capacidade estiverem } \\
\text { preenchidos. }\end{array}$ \\
\hline Acondicionamento & & & & & $\begin{array}{llr}\text { Lixeiras } & \text { estão } & \text { sem } \\
\text { tampa, } & \text { sistema } & \text { de } \\
\text { abertura } & \text { com contato } \\
\text { manual e } & \text { não } & \text { são } \\
\text { resistente } & & \text { a } \\
\text { tombamento. } & & \\
\end{array}$ & $\begin{array}{l}\text { Resolução da ANVISA RDC no 306/04: Os sacos devem estar } \\
\text { contidos em recipientes de material lavável, resistente à } \\
\text { punctura, ruptura, vazamento, tampa provida de sistema de } \\
\text { abertura sem contato manual, com cantos arredondados e } \\
\text { resistente a tombamento. }\end{array}$ \\
\hline Etapas do manejo & H1 & H2 & H3 & H4 & $\begin{array}{l}\text { Não conformidades } \\
\text { observadas }\end{array}$ & Determinações legais \\
\hline Acondicionamento & & & & & $\begin{array}{l}\text { As caixas de papelão dos } \\
\text { Resíduos do grupo E são } \\
\text { reaproveitadas }\end{array}$ & $\begin{array}{l}\text { Resolução da ANVISA RDC } \mathrm{n} \text { - 306/04: Materiais } \\
\text { perfurocortantes, devem ser descartados separadamente }\end{array}$ \\
\hline
\end{tabular}




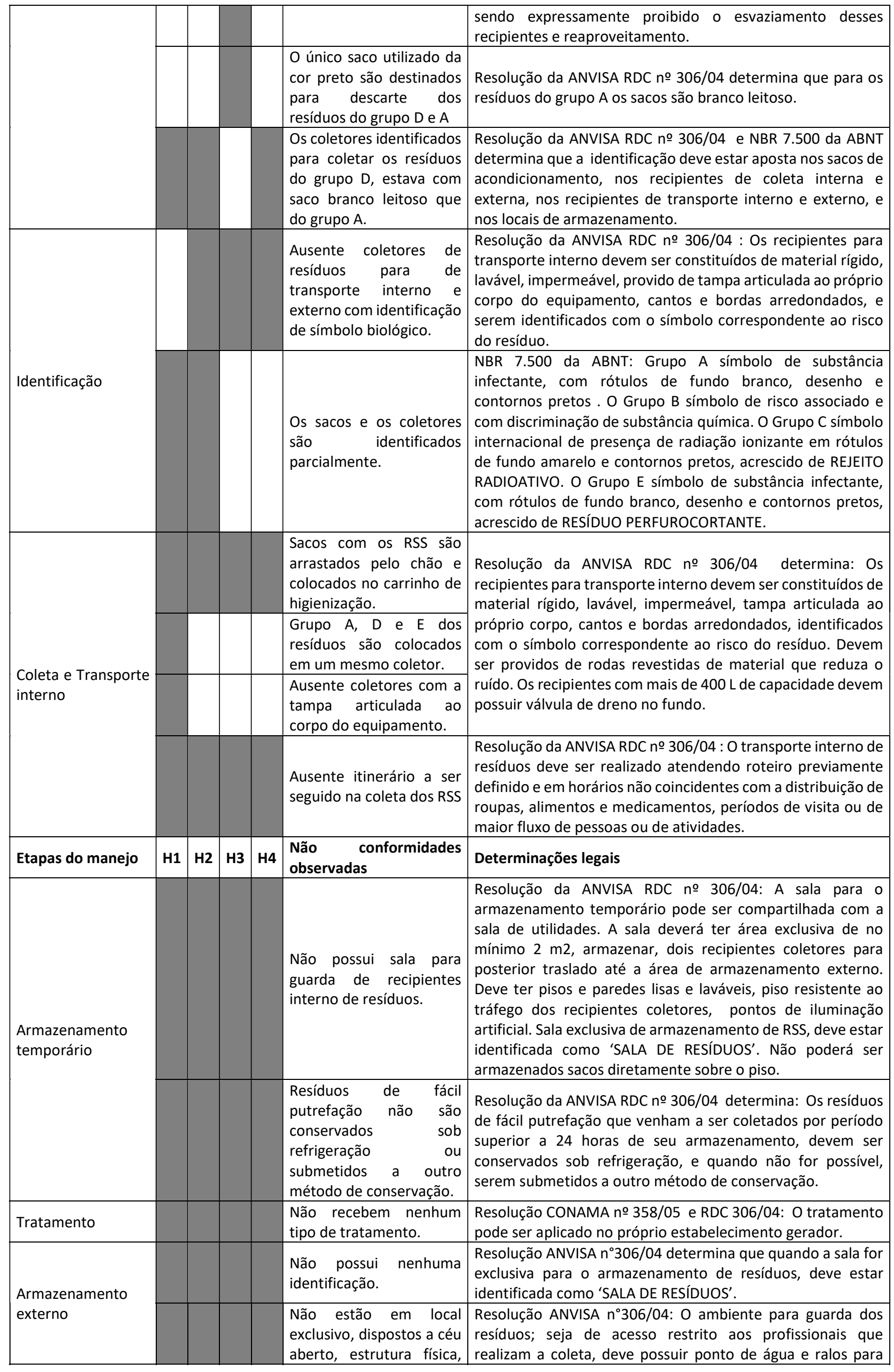




\begin{tabular}{|c|c|c|}
\hline & $\begin{array}{l}\text { elétrica, e } \quad \text { hídrica } \\
\text { ausentes, não é restrito. }\end{array}$ & $\begin{array}{l}\text { escoamento, janelas e portas com proteção à entrada de } \\
\text { insetos e roedores, identificação e paletização dos } \\
\text { dispositivos de acondicionamento. }\end{array}$ \\
\hline \multirow[t]{2}{*}{$\begin{array}{l}\text { Coleta e transporte } \\
\text { externo }\end{array}$} & $\begin{array}{lr}\text { Resíduos do } & \text { grupo D é } \\
\text { realizada pelo Serviço de } \\
\text { Limpezar Pública do } \\
\text { Município } & \text { utilizando } \\
\text { caminhão } & \text { coletor } \\
\text { compactador. } & \end{array}$ & \multirow{2}{*}{$\begin{array}{l}\text { Resolução ANVISA } n^{\circ} 306 / 04 \text {, a coleta e o transporte externo } \\
\text { devem ser feitos respeitando as classes de resíduos, com o } \\
\text { uso de equipamentos e veículos que garantam a integridade } \\
\text { do resíduo desde o ponto de coleta e transporte até a } \\
\text { destinação final e a proteção ao meio ambiente. Veículos } \\
\text { devem possuir identificação de risco conforme o resíduo que } \\
\text { transportam, estar em bom estado de conservação e } \\
\text { higienizados. }\end{array}$} \\
\hline & $\begin{array}{l}\text { RSS Grupo A e E fica a } \\
\text { cargo de uma empresa } \\
\text { contratada que utiliza } \\
\text { veículo tipo baú. }\end{array}$ & \\
\hline
\end{tabular}

Conforme evidencia-se a figura 2 uma das principais dificuldades para realizar a segregação é a ausência de recipientes para os resíduos do grupo A, inexistência de sacos com cor estabelecidas pelas normas regulamentadoras conforme figura 2 imagem (c) e/ ou uma única cor de saco utilizado no estabelecimento ser o da cor preta conforme figura 2 imagem (d), bem como lixeiras quebradas que acarretam riscos ocupacionais pois o profissional precisa durante a rotina de trabalho abrir a lixeira para descartar RSS estando expostos a um possível tombamento da lixeira, como sacos e coletores não são identificados pelos símbolos padronizados conforme a imagem (e) da figura 2 e a ausência de coletores de resíduos para transporte interno e externo com identificação de símbolo biológico contribui diretamente para que a segregação ocorra de maneira inadequada.

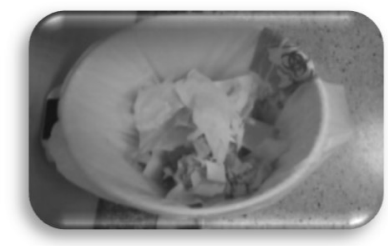

a

Segregação dos resíduos do grupo $D$ com resíduos do grupo A e $E$

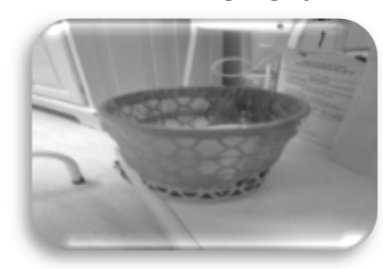

c

Lixeiras que realizam o acondicionamento nos hospitais

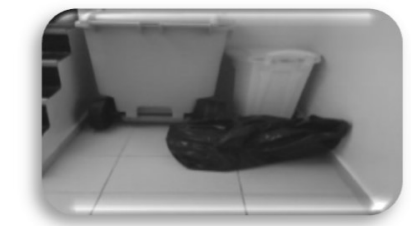

f

Transporte interno dos RSS nos hospitais

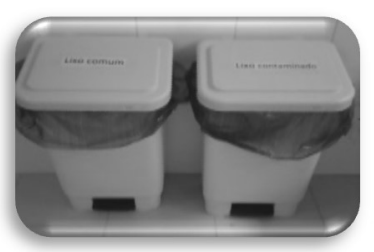

d

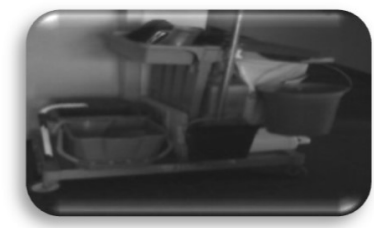

Figura 2: Manejo dos resíduos de serviços de saúde.
Identificação das lixeiras e sacos
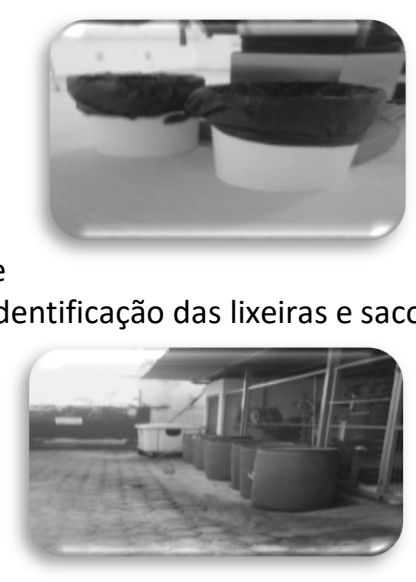

h

Abrigo externo dos RSS nos hospitais

Durante a coleta e transporte interno pode-se observar que resíduos são arrastados pelo chão e transportados no carrinho de higienização conforme imagem (f) e (g) da figura 2, sendo ainda transportados em qualquer horário do dia. $\mathrm{O}$ abrigo de RSS como pode ser visualizado na imagem (h), (i) da figura 2, não estão em local exclusivo, dispostos a céu aberto, não possui identificação e não é restrito aos profissionais 
envolvidos com o manejo dos RSS, o trajeto para o traslado desde a geração até o armazenamento externo permite parcialmente o livre acesso dos recipientes coletores de resíduos o piso não possui revestimento à abrasão, superfície plana, regular, antiderrapante e ou rampa, já na parte externa do hospital onde estão os RSS, possibilita a entrada de funcionários, alimentos para a cozinha.

\section{Pesagem dos Resíduos dos Serviços de Saúde:}

Os RSS gerados nos estabelecimentos de saúde foram pesados com a utilização de balança digital após a disposição no abrigo externo durante sete dias sempre na primeira semana do mês no período de 24 horas, sendo necessário a pesagem dos RSS em vários momentos sendo separados e pesados por funcionários selecionados, orientados e supervisionados.

Os resultados das pesagens foram registrados em planilhas de Excel permitindo conhecer o montante dos RSS gerados semanalmente dos quatro hospitais. Foi realizado a contagem diária dos pacientes internados de todos os setores tendo como fonte de informação o censo hospitalar, este controle foi executado durante sete dias sempre na primeira semana do mês nos quatros hospitais pesquisados. Os resultados apresentados nas tabelas 1, 2, 3 e 4 estão expressos em números absolutos e percentuais. Para calcular o percentual dos RSS, partiu-se do montante total de resíduos gerados em Kg por estabelecimento de saúde, este resultado foi dividido pela quantidade de leitos ocupados por estabelecimento de saúde.

Na tabela 1, verifica-se que no mês de setembro o $\mathrm{H} 1$ teve a maior quantidade de resíduo gerado com 0,658 kg/paciente, obstante foi o mês que teve 814 leitos ocupados não sendo maior número, o mês que teve o maior número de leitos ocupados foi agosto com 1162 atendimentos com 0,355 kg/leito. O mês de dezembro teve a menor quantidade de resíduos com 0,288 kg/leito com 733 leitos ocupados.

Tabela 1: Quantidade de resíduos dos serviços de saúde coletados e leito hospitalar ocupado da primeira semana de cada mês de agosto de 2016 a janeiro de 2017 no hospital 1 (H1).

\begin{tabular}{|l|l|l|l|}
\hline \multicolumn{2}{|l|}{ Hospital 01 } & Número de Internações & Kg/leito \\
\hline Período & Kg/ RSS & & \\
\hline Ago/16 & & 1162 & 0,355 \\
\hline Set/16 & 413 & 814 & 0,658 \\
\hline Out/16 & 536 & 1055 & 0,387 \\
\hline Nov/16 & 408 & 700 & 0,379 \\
\hline Dez/16 & 265 & $\mathbf{7 3 3}$ & 0,288 \\
\hline Jan/17 & 211 & 900 & 0,363 \\
\hline Total & 327 & $\mathbf{5 3 6 4}$ & $\mathbf{0 , 4 0 3}$ \\
\hline
\end{tabular}

Na tabela 2, evidencia-se que no mês de janeiro o $\mathrm{H} 2$ teve a maior quantidade de resíduo gerado de 0,339 kg/leito, obstante foi o mês que teve a menor quantidade de leitos ocupados com 622 , o mês que teve o maior número de leitos ocupados foi agosto com 851 leitos ocupados com 0,135 kg/leito com a menor quantidade de resíduos. Apesar de possuir 4658 leitos ocupados teve o percentual de 0,199 kg/paciente de resíduo infectante. A tabela 3, mostra também que a quantidade de resíduos no estabelecimento H3 em todos os meses ultrapassam a quantidade de 1,479 kg/leito, chegando em agosto com somente 97 leitos ocupados a geração de 2,062 kg/leito de resíduo infectante. E para somente 469 leitos ocupados o percentual de $1,642 \mathrm{~kg} /$ paciente. 
Tabela 2: Quantidade de resíduos dos serviços de saúde coletados e leito hospitalar ocupado da primeira semana de cada mês de agosto de 2016 a janeiro de 2017 no hospital 2 (H2).

\begin{tabular}{|l|l|l|l|}
\hline & Hospital 02 & Kg/leito \\
\hline Período & Kg/ RSS & & \\
\hline & & 851 & 0,135 \\
\hline Ago/16 & 115 & 787 & 0,164 \\
\hline Set/16 & 129 & 763 & 0,195 \\
\hline Out/16 & 149 & 793 & 0,214 \\
\hline Nov/16 & 170 & 842 & 0,181 \\
\hline Dez/16 & 152 & 622 & 0,339 \\
\hline Jan/17 & 210,95 & $\mathbf{4 6 5 8}$ & $\mathbf{0 , 1 9 9}$ \\
\hline Total & $\mathbf{9 2 5 , 9 5}$ & & \\
\hline
\end{tabular}

Tabela 3: Quantidade de resíduos dos serviços de saúde coletados e leito hospitalar ocupado da primeira semana de cada mês de agosto de 2016 a janeiro de 2017 no hospital 3 (H3).

\begin{tabular}{|l|l|l|l|}
\hline & Hospital 04 & Kg/leito \\
\hline Período & Kg/ RSS & & \\
\hline & & 97 & 2,062 \\
\hline Ago/16 & 200 & 90 & 1,500 \\
\hline Set/16 & 90 & 76 & 1,645 \\
\hline Out/16 & 125 & 85 & 1,529 \\
\hline Nov/16 & 130 & 71 & 1,479 \\
\hline Dez/16 & 105 & 80 & 1,500 \\
\hline Jan/17 & 120 & $\mathbf{4 6 9}$ & $\mathbf{1 , 6 4 2}$ \\
\hline Total & $\mathbf{7 7 0}$ & & \\
\hline
\end{tabular}

A tabela 4 revela que 24 leitos ocupados geraram o percentual de 5,208 kg/leito de resíduos infectantes. A tabela evidencia que o menor percentual foi em janeiro de 2017 com 2,206 kg/leito sendo o menor percentual do kg/leito de RSS do estabelecimento. E com apenas 286 leitos ocupados atingiu a 3,009 $\mathrm{kg} / \mathrm{leito}$.

Tabela 4: Quantidade de resíduos dos serviços de saúde coletados e leito hospitalar ocupado da primeira semana de cada mês de agosto de 2016 a janeiro de 2017 no hospital 4 (H4)

\begin{tabular}{|l|l|l|l|}
\hline & Hospital 04 & Número de Internações & Kg/leito \\
\hline Período & Kg/ RSS & & 5,208 \\
\hline Ago/16 & & 24 & 2,867 \\
\hline Set/16 & 125 & 30 & 3,162 \\
\hline Out/16 & 86 & 37 & 3,689 \\
\hline Nov/16 & 117 & 45 & 3,306 \\
\hline Dez/16 & 166 & 49 & 2,026 \\
\hline Jan/17 & 162 & 101 & $\mathbf{3 , 0 0 9}$ \\
\hline Total & $\mathbf{2 0 4 , 6}$ & $\mathbf{2 8 6}$ & \\
\hline
\end{tabular}

A figura 3, apresenta o resultado da somatória dos resíduos infectantes, gerados nos setores da Clínica Médica, Cirúrgica, Maternidade, Pediatria, Unidade de Terapia Intensiva Adulta (UTI), Centro Cirúrgico, Central de Material e Esterilização, Atendimento de Emergência, Serviços de Nutrição e Dietética, Lavanderia, Farmácia, Almoxarifado, Setor de imagem, Setores Administrativos dos quatro estabelecimentos de saúde durante o período em que o estudo foi desenvolvido. Analisando a figura 8 , constatou-se a prevalência do $\mathrm{H} 4$ com 3,009 kg/leito e do H3 com 1,642 kg/leito de resíduo infectante, quando comparado aos $\mathrm{H} 1$ com 0,403 kg/leito e $\mathrm{H} 2$ com 0,199 de resíduo infectante sendo este com o menor percentual de RSS. 


\begin{tabular}{|c|c|c|c|c|c|c|c|}
\hline & 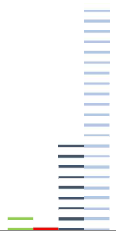 & 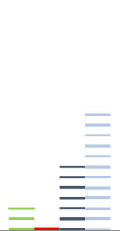 & $-\underline{\equiv}$ & 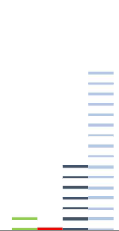 & $\begin{array}{l}\text { 三 } \\
\text { 三 } \\
\text { 三E }\end{array}$ & $\underline{\equiv}$ & 韮 \\
\hline & ago/16 & set/16 & out/16 & nov/16 & $\mathrm{dez} / 16$ & jan/17 & Total \\
\hline$=\mathrm{H} 1 \mathrm{Kg} / \mathrm{RSS} / \mathrm{leito} / \mathrm{dia} \%$ & 0,355 & 0,658 & 0,387 & 0,379 & 0,288 & 0,363 & 0,403 \\
\hline - H2 Kg/RSS/leito/dia \% & 0,135 & 0,164 & 0,195 & 0,214 & 0,181 & 0,339 & 0,199 \\
\hline = H3 Kg/RSS/leito/dia \% & 2,062 & 1,500 & 1,645 & 1,529 & 1,479 & 1,500 & 1,642 \\
\hline$=\mathrm{H} 4 \mathrm{Kg} / \mathrm{RSS} / \mathrm{leito} / \mathrm{dia} \%$ & 5,208 & 2,867 & 3,162 & 3,689 & 3,306 & 2,026 & 3,009 \\
\hline
\end{tabular}

Figura 3: Distribuição da quantidade de resíduo infectante por $\mathrm{Kg} /$ leito de quatro estabelecimentos de saúde de agosto de 2016 a janeiro de 2017.

\section{DISCUSSÃO}

Todos os hospitais possuem o PGRSS incompleto conforme quadro 2 esse resultado vai de encontro com o encontrado por Pereira et al. (2013) que onde foi analisado que na prática ainda não se observa a implementação de um plano gerencial adequado ou a sua existência quer seja por razões de infraestrutura, recursos financeiros, recursos humanos ou conhecimento.

Foi possível observar que as dificuldades para realizar a segregação está fortemente atrelada a ausência de conhecimento dos profissionais envolvidos no manejo dos RSS, ausência sacos coletores conforme estabelecidos pelas normas regulamentadoras, lixeiras fora dos padrões e quebradas, ausente identificação com símbolos padronizados contribuem significativamente para que a segregação ocorra de forma inadequada, ou seja, os resíduos do grupo D sendo misturado com os resíduos do grupo A contaminando o resíduo que poderia ser disponibilizado para a reciclagem conforme expressa quadro 3 e figura 2 imagem a e b. Essa ocorrência foi identificado por vários autores quanto à segregação, é que os resíduos são descartados de maneira inadequada não realizando a coleta seletiva, promovendo a contaminação de todo o resíduo descartado (NITSCHE et al., 2014; SANTOS et al., 2012).

Para Oliveira et al. (2017) e Mahler et al. (2017) os resíduos devem ser tratados conforme suas classificações, quando a segregação não ocorre no momento e local da sua geração todos os resíduos se tornam infectantes. Essa dificuldade encontrada impacta diretamente nas questões financeiras do estabelecimento de saúde decorrente do aumento no custo para o descarte dos RSS e o tratamento inadequado para cada grupo de resíduo, além de riscos ocupacionais ao profissionais envolvidos no manejo dos RSS que durante a coleta podem sofrer acidentes com os perfurocortantes.

Conforme o quadro 3 os coletores são identificados de forma inadequada, quando o coletor está identificado para coleta de resíduos do grupo D ele está com o saco para descarte dos resíduos do grupo A, os contenedores são inexistentes no hospital H01. Esses dados foram identificados no estudo de Oliveira (2014) que verificou que as unidades não dispõem de sacos plásticos e contenedores adequados para fazerem o acondicionamento correto dos seus resíduos, procedimento imprescindível ao gerenciamento correto dos RSS. Gomes e Esteves (2012) identificaram que os estabelecimentos de saúde não realizavam o acondicionamento dos RSS conforme prevê a RDC 306/2004 (BRASIL, 2004) os RSS estavam acondicionados 
em garrafas PET, os sacos utilizados para acondicionarem os resíduos do grupo $D$ não possuíam nenhuma identificação e recebiam os RSS, expondo e criando situação de risco para os profissionais, saúde pública e ao meio ambiente.

Durante a coleta e o transporte interno pode-se observar que resíduos são arrastados pelo chão e transportados no carrinho de higienização conforme quadro 3 e imagem (f) e (g) da figura 7, sendo ainda transportados em qualquer horário do dia. Dutra et al. (2012) identificaram que este acontecimento ocorre, frequentemente e coincide com os horários de distribuição de roupas e visita de acompanhantes e no transporte interno os RSS não são identificados, Castro et al. (2014) identifica que quanto a coleta e o transporte interno dos RSS, é frequente a falta de definição de horários, turnos e frequência de coletas. 0 transporte é realizado de maneira manual, não havendo disposição de carrinho coletor identificado com o símbolo para cada grupo de resíduo.

Sobre o local para o armazenamento temporário não foi identificado nos quatro estabelecimentos de saúde conforme registrado no quadro 3. Dutra et al. (2012) identificou que quando o armazenamento temporário é existente está subdimensionado, ou não atende a legislação e se encontra sem identificação. É possível ainda identificar no quadro 3 que os estabelecimentos de saúde não realizam nenhum tratamento para os RSS, este fato foi identificado por Ramos et al. (2011) e Melo et al. (2013) que relatam que o tratamento prévio do RSS muitas vezes não ocorre como o previsto nos instrumentos legais e conforme Aduan (2014) e Souza et al. (2015) alguns estabelecimentos não realizam nenhum tipo de tratamento.

Em um trabalho realizado no munícipio de Ariquemes (RO), que também pertence a mesorregião do leste rondoniense, Borille et al. (2013) verificaram que o tratamento do RSS da rede pública do município não obedecia às normas da ANVISA e do CONAMA, sendo os RSS despejados e queimados em incineradores improvisados e a céu aberto, sem tratamento dos gases tóxicos sem qualquer estratégia de segurança.

O abrigo de resíduos como pode ser analisado no quadro 3 e visualizado imagem (h), (i) da figura 7, não estão em local exclusivo e estão dispostos a céu aberto, não possui nenhuma identificação, e não é restrito aos profissionais envolvidos com o manejo dos RSS, pois o trajeto para o traslado desde a geração até o armazenamento externo permite parcialmente o livre acesso dos recipientes coletores de resíduos o piso não possui revestimento à abrasão, superfície não é plana, regular, antiderrapante e não possui rampa de acordo com a RDC no 50/2002 ANVISA, já na parte externa do hospital onde estão os RSS, possibilita a entrada de funcionários, alimentos para a cozinha.

Ramos et al. (2011) em seus trabalhos encontraram falhas nos armazenamentos externos que apresentavam deficiências de infraestruturas nas instalações elétricas e hidráulicas, ventilação inexistente e ausência de baias individualizadas para separar os vários tipos de resíduos (comuns e infectantes). Para Macedo et al. 2013 a localização dos armazenamentos externos também não possuem restrição de acesso a pessoas estranhas, as características físicas e dimensões são insuficientes pelo volume de RSS gerados. Verifica-se também falta de escoamento adequado das águas de lavagem e a porta de entrada não impede a entrada de vetores como roedores. 
Quanto a coleta externa nos quatro estabelecimentos de saúde os resíduos do grupo $D$ é realizada pelo Serviço de Limpeza Pública do Município utilizando caminhão coletor compactador, para os RSS Grupo A e E fica a cargo de uma empresa contratada especializada que utiliza veículo tipo baú. No município de JiParaná et al. (2014) indicam que os resíduos são disponibilizados em valas a céu aberto com apenas uma cobertura de terra do próprio local, o que proporciona a produção de chorume e consequentemente contamina o solo e os recursos hídricos daquela região.

Segundo Ziegler (2010) a região Norte é uma das regiões brasileiras que mais se criam lixões a 'céu aberto', e pior, grande parte destes poluentes não tem nem se quer previsão para estarem lacrados, geram um odor terrível, doenças e também riscos ao bem-estar daqueles menos providos de recursos que vão em busca de algo para suprirem suas necessidades, os populares catadores de lixo.

Por meio da avaliação sistemática foi possível identificar que os procedimentos de manejo dos RSS não obedece o que determina as legislações vigentes no país, particularmente a RDC 306/04 (BRASIL, 2004) que estabelece no Art. 4ำ quando ocorrer inobservância do disposto nesta Resolução e seu Regulamento Técnico configura infração sanitária e sujeitará o infrator às penalidades previstas na Lei no. 6.437, de 20 de agosto de 1977, sem prejuízo das responsabilidades civil e penal cabíveis.

Referente a pesagem dos RSS conforme as informações da figura 3, constatou-se a prevalência do H4 com 3,009 kg/leito e do H3 com 1,642 kg/leito de resíduo infectante, quando comparado aos H1 com 0,403 kg/leito e H2 com 0,199 de resíduo infectante sendo este com o menor percentual de RSS. Estes dados condizem parcialmente com o relatório da ABRELPE (2015) que indica que no estado de Rondônia em 2015 foram coletados 1.011 t.ano o que corresponde a 0,572 kg/hab/ano em 20161.014 t.ano o que corresponde a $0,567 \mathrm{~kg} / \mathrm{hab} /$.

\section{CONCLUSÕES}

Considerando os resultados desta pesquisa, podemos tecer algumas conclusões quanto aos principais desafios dos hospitais quanto a implementação do PGRSS foram divididas em três categorias: a primeira traz a síntese da análise dos documentos e registros do PGRSS, a segunda descreve a conclusão da observação do comportamento dos profissionais no manejo dos RSS durante a visita aos setores do estabelecimento de saúde, a terceira descreve o panorama da quantidade de RSS gerados nos hospitais particulares de pequeno porte da mesorregião do leste rondoniense .

A síntese da análise dos documentos e registros do PGRSS é alarmante pois do ponto de vista técnico os quatro hospitais não possuem um PGRSS com a descrição de todas as etapas do manejo dos resíduos, o que sinaliza a necessidade urgente de realizar a reestruturação dos PGRSS com complementações descritas na RDC 306/2004 (BRASIL, 2004). Este fato é preocupante pois o acervo documental completo do PGRSS possibilita aos gestores o diagnostico situacional dos RSS nos hospitais, elaboração de um planejamento com metas financeiras, de recursos humanos, proteção a saúde dos trabalhadores, da saúde pública e do meio ambiente, redução e reciclagem dos resíduos, possibilitando realizar uma avaliação após a implementação 
para ajuste dos pontos que não atingiram a meta e permitindo a implementação do PGRSS de forma planejada.

O fato dos hospitais não terem os PGRSS com a descrição completa, evidentemente inferiu em etapas fundamentais como podemos observar no comportamento dos profissionais durante o manejo dos RSS que evidenciou que na prática os profissionais não realizam o manejo dos RSS em todas as etapas operacionais conforme prevê a RDC 306/2004 (BRASIL, 2004). Conclui-se que a não conformidade identificada nessa categoria está fortemente vinculada não somente a ausência de conhecimento, mas também com a ausência dos recursos materiais e estruturais.

Quanto ao panorama da quantidade de RSS gerados pelos hospitais os dados do gráfico 1 conclui que a prevalência do H4 com 3,009 kg/leito e do H3 com 1,642 kg/leito de resíduo infectante, são alarmantes o que enfatiza mais uma vez o desafio dos hospitais. Esse panorama é meramente uma consequência da ausência do PGRSS completo, profissionais capacitados, disponibilização de recursos materiais e estrutura física adequada.

O resultado da pesquisa expôs que as principais dificuldades para realizar a implementação do PGRSS vai desde a elaboração do PGRSS com todas as etapas previstas na legislação, investimentos financeiro em recursos materiais, físicos e humanos, conhecimento das legislações para cada etapa do manejo dos RSS e capacitação técnica e ética dos profissionais.

Devemos considerar que como sugestão para garantir que os profissionais realizem a implementação do PGRSS deve existir um exercício diário de treinamentos, envolvimento dos profissionais na elaboração do PGRSS, investimento financeiro, e analise de processos de reciclagem dos resíduos infectantes seria um caminho para solucionar e minimizar os RSS que são destinados a lixões a céu aberto, colocando em risco a saúde dos trabalhadores e a saúde pública e causando danos ao meio ambiente.

\section{REFERÊNCIAS}

ADUAN, S.; BRAGA, F. S.; ZONDONADE, E.; SALLES, D. C.; NOIL, A. M.; LANGE, L. C.. Avaliação dos resíduos de serviços de saúde do Grupo A em hospitais de Vitória (ES), Brasil. Eng. Sanit. Ambient., Rio de Janeiro, v.19, n.2, p.133141, 2014. DOI: http://dx.doi.org/10.1590/S141341522014000200004

ALVES, S. B.; SOUZA, A. C.; TIPPLE, A. F. V.; REZENDE, K. C. D.; RIBEIRO, F.; GOULART, E.. Manejo de resíduos gerados na assistência domiciliar pela Estratégia de Saúde da Família. Rev. bras. enferm., Brasília, v.65, n.1, p.128-134, 2012. DOI: http://dx.doi.org/10.1590/S0034$\underline{71672012000100019}$

ABRELPE. Associação Brasileira de Empresas de Limpeza Pública e Resíduos Especiais. Panorama dos resíduos sólidos no Brasil. 2015.

ABRELPE. Associação Brasileira de Empresas de Limpeza Pública e Resíduos Especiais. NBR 12807: Resíduos de serviços de saúde - terminologias. Rio de Janeiro: 1993a. resíduos de serviços de saúde: procedimentos. Rio de Janeiro: $1993 \mathrm{~b}$.

BENTO, D. G.; COSTA, R. L.; HOMEM, J.; KLOCK, P.. O gerenciamento de resíduos de serviço de saúde sob a ótica dos profissionais de enfermagem. Texto contexto - enferm., Florianópolis, v.26, n.1, 2017. DOI: http://dx.doi.org/10.1590/0104-07072017006680015

BEZERRA, R. R.; ANDRADE, N. L. R.. Variáveis químicas e biológicas do igarapé Riachuelo como indicadoras de poluição urbana na cidade de Ji-Paraná (RO). Iniciação Científica CESUMAR, v.16, n.2, p.163-169, 2014.

BORILLE, D. B.; MENEGUETTI, N. F. S. P.; ZAN, R. A.; MENEGUETTI, D. U. O.. Gestão dos resíduos sólidos de serviços e saúde no município de Ariquemes, Rondônia: Um problema negligenciado. Revista de Epidemiologia e Controle de Infecção, Santa Cruz do Sul, v.3, n.3, p.105-107, 2013.

BRASIL. Ministério da Saúde. Secretária Nacional de Ações Básicas de Saúde. Conceitos e definições em Saúde. Brasília, 1977. 
BRASIL. Ministério da Saúde. Agência Nacional de Vigilância Sanitária. Resolução da Diretoria Colegiada: RDC n 306. Brasília: Diário Oficial da União, 2004.

BRASIL. Ministério do Meio Ambiente e da Amazônia Legal. Resolução CONAMA n.358. Brasília: Diário Oficial da União, 2005.

BIANCHI, B. B.; BARROS, L. M.; SILVA, L. A. S.; BESERRA, F. M.; CAETANO, J. A. C.. Estratégia Educativa sobre Manejo de Resíduos Sólidos de Saúde na Unimed de Terapia Intensiva. Revista Brasileira em Promoção da Saúde, v.29, n.2, 2016.

CASTRO, R. R.; GUIMARÃES, O. S.; LIMA, V. M. L.; LOPES, C. D. F.; CHAVES, E. S.. Gerenciamento dos resíduos de serviços de saúde em um hospital de pequeno porte. Revista Rene, v.15, n.5, p.860-868, 2014.

CENTENARO, W. L. A.; DALLAGO, R. M.; CENTENARO, A. M.. Gerenciamento de Resíduos de Serviços de Saúde macrorregião Geográfica de Erechim/RS. Revista Perspectiva, v.36, n.133, p.223-236, 2012.

DOI, K. M.; MOURA, G. M. S. S.. Resíduos sólidos de serviços de saúde: uma fotografia do comprometimento da equipe de enfermagem. Rev. Gaúcha Enferm., Porto Alegre, v.32, n.2, p.338-344, 2011. DOI: http://dx.doi.org/10.1590/S1983-14472011000200018

DUTRA, L. M. A.; MONTEIRO, P. S.. Gerenciamento de resíduos sólidos em um hospital de ensino em Brasília. Comunicação em Ciências da Saúde, Brasília, v.22, n.4, p.305-314, 2012.

GESSNER, R.; PIOSIADLO, L. C. M.; FONSECA, R. M. G. S.; LAROCCA, L. M.. O manejo dos resíduos dos serviços de saúde: um problema a ser enfrentado. Cogitare Enfermagem, v.18, n.1, 2013.

GOMES, L. P.; ESTEVES, R. R. V.. Análise do sistema de gerenciamento dos resíduos de serviços de saúde nos municípios da bacia hidrográfica do Rio dos Sinos, Rio Grande do Sul, Brasil. Eng. Sanit. Ambient., Rio de Janeiro, v.17, n.4, p.377-384, 2012.

IBGE. Instituto Brasileiro de Geografia e Estatística. Pesquisa Nacional de Saneamento Básico 2008.

KNEIPP, J. M.; BEURON, T. A.; CARPES, A. M.; PERLIN, A. P.; GOMES, C. M.. Gerenciamento de Resíduos Sólidos no Serviço de Saúde. Revista de Administração Hospitalar e Inovação em Saúde, v. 6, n.6, p.22-34, 2011.

MAHLER, C. F.; MOURA, L. L.. Resíduos de Serviços de Saúde (RSS): Uma abordagem qualitativa. RISTI, Porto, n.23, p.4660, 2017.

MELO, R. H. V.; MELO, R. M. A. L.; MELO, R. O. F.; RÊGO, G. VILAR, R. L. A.. Um Estudo sobre o gerenciamento dos resíduos sólidos de serviços de Saúde na Liga Norte Riograndenses contra o câncer. Revista Brasileira de Inovação Tecnológica em Saúde, v.4, n.4, 2014.

MENDONÇA, I. V. S.; OLIVEIR, L.P.; GOMES, S. C. S.; TAKAYANAGUI, A. M. M.; CALDAS, A. J. M.. Gerenciamento de Resíduos de Serviços de Saúde: Uma questão de planejamento. Rev. Pesq. Saúde, v.18, n.1, p.7-12, 2017.

MULLER, A. M.; NARA, E.; SILVEIRA, D.; KIPPER, L. M.. Um olhar exploratório sobre os resíduos de serviços de saúde para os cursos da área da saúde num universidade comunitária do Sul do Brasil. Revista Eletrônica em Gestão, Educação e Tecnologia Ambiental - REGET, v.17, n.17, p.2227-3335, 2013.

NITSCHE, M. J. T.; ARAÚJO, P. A.; MATARAZZO, A. A.; OLBRICH, S. R. L. R.; ALVES, M. V. M. F. F.. Resíduos de serviço de saúde em unidade de terapia intensiva do prontosocorro do Hospital das Clínicas da Faculdade de Medicina de Botucatu-UNESP. Revista Ciência em Extensão, v.10, n.3, 2014.

OLIVEIRA, L. L. O.; SOUZA, P. M.; CLEMENTINO, F. S.; PAIVA, S. C.; ROCHA, F. D. L. J.. Resíduos dos serviços de saúde: desafios e perspectivas na atenção primária. Revista enfermagem UERJ, Rio de Janeiro, v.22, n.1, 2014.

OPAS. Organização Pan-Americana de Saúde. Guia para o manejo interno de resíduos sólidos em estabelecimentos de saúde. Brasília: OPAS, 1997.

PEREIRA, M. S.; SOUZA, A. C. S.; TIPPLE, A. F. V.; REZENDE, F.; RODRIGUES, E. G.. Waste management in non-hospital emergency units. Rev. Latino-Am. Enfermagem, Ribeirão Preto, v.21, p.259-266, 2013.

RAMOS, Y. S.; PESSOA, Y. S. R. Q.; RAMOS, Y. S.; NETTO, F. B. A.; PESSOA, C. E. Q.. Vulnerabilidade no manejo dos resíduos de serviços de saúde de João Pessoa (PB, Brasil). Ciência e Saúde Coletiva, v.16, n.8, p.3553-3560, 2011.

RIZZON, F.; NODARI, C. H.; REIS, Z. C.. Desafio no Gerenciamento de Resíduos em Serviços Públicos de Saúde. Revista de Gestão em Sistemas de Saúde - RGSS, v.4, n.1, 2015.

ROSA, C. D. P.; MATHIAS, D. KOMATA, C. C.. Custo de Gerenciamento de Resíduos de Serviços de Saúde (RSS): Estudo de Caso da Unidade de Terapia Intensiva de Infectologia de um Hospital Público em São Paulo Revista de Gestão Ambiental e Sustentabilidade-GeAS, v.4, n.2, 2015.

SANTOS, M. A.; SOUZA, A. O.. Conhecimento de enfermeiros da Estratégia Saúde da Família sobre resíduos dos serviços de saúde. Rev. bras. enferm., Brasília, v.65, n.4, p.645-652, 2012.

SILVA, D. F.; VON SPERLING, E.; BARROS, R. T. V.. Avaliação do gerenciamento dos resíduos de serviços de saúde em municípios da região metropolitana de Belo Horizonte (Brasil). Eng. Sanit. Ambient., Rio de Janeiro, v.19, n.3, p.251-262, 2014.

SILVA, G. F.; GANDOLFI, J. C.; FRAGA, C. I. M.. A percepção de educadores quanto ao saneamento e a saúde ambiental na microrregião de Colorado do Oeste, Rondônia. In: CONGRESSO BRASILEIRO DE GESTÃO AMBIENTAL, 5. Anais. Belo Horizonte, 2014.

SOUZA, T. C.; OLIVEIRA, C. F.; SARTORI, H. J. F.. Diagnóstico do gerenciamento de resíduos de serviços de saúde em estabelecimentos públicos de municípios que recebem 
Imposto sobre Circulação de Mercadorias e Serviços ecológico no Estado de Minas Gerais. Eng. Sanit. Ambient., Rio de Janeiro, v.20, n.4, p.571-580.

WHO. World Health Organization. Waste from health: care activities. Factsheet $n^{\circ} 253$. Geneva: WHO, 2011.
WHO. World Health Organization. Safe management of wastes from health-care activities. 2 ed. World Health Organization, 2014.

A CBPC - Companhia Brasileira de Produção Científica (CNPJ: 11.221.422/0001-03) detém os direitos materiais desta publicação. Os direitos referem-se à publicação do trabalho em qualquer parte do mundo, incluindo os direitos às renovações, expansões e disseminações da contribuição, bem como outros direitos subsidiários. Todos os trabalhos publicados eletronicamente poderão posteriormente ser publicados em coletâneas impressas sob coordenação da Sustenere Publishing, da Companhia Brasileira de Produção Científica e seus parceiros autorizados. Os (as) autores (as) preservam os direitos autorais, mas não têm permissão para a publicação da contribuição em outro meio, impresso ou digital, em português ou em tradução. 